\title{
EXPERIENCIAS EN LA DOCENCIA DE HISTORIA DE LA EDUCACIÓN, EN LA FACULTAD DE PEDAGOGÍA DE LA UNIVERSIDAD PANAMERICANA
}

\author{
Lucina Moreno Valle Suárez
}

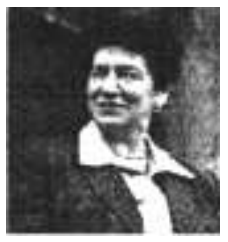

Doctora en Humanidades, Centro Universitario de la Ciudad de México. Doctora en Humanidades (Historia), Universidad Autónoma Metropolitana, Unidad Iztapalapa (UAMI).

Maestra en Pedagogía, Universidad Panamericana. Licenciada en Historia, Universidad Nacional Autónoma de México.

Investigadora y coordinadora del Departamento de Tecnología educativa; profesora de Historia de la educación, Metodología de la investigación y Sociología de la educación, Facultad de Pedagogía, Universidad Panamericana, Autora de varias obras, siendo la última: La vida de Carlos María de Bustamante, Universidad Autónoma Metropolitana Iztapalapa-Biblioteca mexicana herreriana.

Correo electrónico: [1morenov@up.edu.mx].

\section{RESUMEN}

La enseñanza de la historia debe responder a una necesidad del futuro pedagogo. Por ello habrá que interrogarse: ¿Para qué le interesa a un estudiante de la licenciatura dedicar tiempo a la historia de la educación? Esta pregunta se ha planteado repetidas veces a lo largo de diez y nueve años de docencia y especialmente cuando se revisan los planes de estudio. Finalmente puede concluirse que un pedagogo necesita conocer la historia para integrar un diagnóstico efectivo de acuerdo a la realidad en la que está 
inmerso. Es frase común entre los pedagogos que la historia sirve «para que no nos tomen el pelo», pues «no hay nada nuevo bajo el sol», como asienta la sabiduría popular inspirada en escritos anteriores a Cristo (Eclesiastés 1, 9-11).

Palabras claves: historia; historia de la educación; diagnóstico pedagógico; intervención educativa.

\section{ABSTRACT}

Histoly's teaching must answer to future pedagogue's necessity. He should have to make himself the question: What is the interest for bachelor's degree students to dedi cate time to education history? This question has been proposed many times through nineteen years long of docent work and especially when they review the studies plan. Finally it is possible to condude that a pedagogue needs to know the history for the integer and effective diagnosis according to reality into he is immersed.

Is a common phrase between pedagogues to say that history serves for "they do not pull someone's leg», since "there is not new something below the sun» as the folk wisdom says, inspired in written documents previous to Christ (Eclesiastés 1, 9-11)

Key words: history; education history; diagnosis.

\section{DIAGNÓSTICO, PLANEACIÓN, INTERVENCIÓN, EVALUACIÓN}

El diagnóstico pedagógico es indispensable para la planeación e implementación de una intervención educativa y, de acuerdo a Quintiliano, «si la naturaleza bastara, ociosa sería la 
educación». Este aforismo no tiene desperdicio. La educación complementa lo que la naturaleza proporciona y como afirma un científico: «La cultura no está en los genes...» ', se puede adquirir, cambiar, combinar, etcétera, y para ello hay que diagnosticar, planear, realizar y evaluar.

La historia está inmersa en el campo de conocimiento de la sociedad. Podría afirmarse que la sociología conjuga el hacer en presente y la historia en pretérito. En esencia se trata del mismo saber. El conocimiento de lo social le sirve al pedagogo para detectar y diagnosticar problemas que ameriten su intervención. No hay que olvidar que la historia es el laboratorio de la sociología. Para analizar la sociedad, puede partirse de varios puntos de referencia.

De acuerdo al pensamiento de Hoffner ${ }^{2}$ con enriquecimiento de otros autores, se ha establecido un patrón de análisis social que permite al pedagogo abordar el estudio de la sociedad independientemente del tiempo y del espacio. Se trata de fijar las estructuras permanentes de la sociedad que posibiliten realizar un diagnóstico más preciso. En la siguiente tabla se presenta, en la primera columna, lo que proponemos como estructuras permanentes de la sociedad. El derecho o el marco jurídico quedan implícitos en todos los aspectos. Todos juntos forman la cultura transmitida a través de la educación informal y/o formal. En la segunda columna están los elementos que no son excluyentes de otros. En la tercera se ejemplifica, y en la cuarta se acota la observación.

\footnotetext{
LEWONTIN, R., et al., No está en los genes. Racismo, genética e ideología. HOFFNER, J., Manual de doctrina social cristiana; LLANO, A., La nueva sensibilidad.
} 


\section{EJES TEMÁTICOS PARA EL ANÁLISIS DE SITUACIONES HISTÓRICAS}

\begin{tabular}{|c|c|c|c|}
\hline $\begin{array}{l}\text { Tiempo. } \\
\text { Espacio, }\end{array}$ & Tecnología. & $\begin{array}{l}\text { Uso o no de la } \\
\text { electricidad, } \\
\text { navegación. }\end{array}$ & $\begin{array}{l}\text { La utilizan o } \\
\text { la rechazan. }\end{array}$ \\
\hline & Familia. & $\begin{array}{l}\text { Monogámico, } \\
\text { poligámico, } \\
\text { heterosexual, } \\
\text { extendida... } \\
\text { Costumbres, ritos, } \\
\text { tradiciones. }\end{array}$ & $\begin{array}{l}\text { Modelo más } \\
\text { frecuente. }\end{array}$ \\
\hline & Economía. & $\begin{array}{l}\text { Comunitaria o } \\
\text { individualista. }\end{array}$ & $\begin{array}{l}\text { Modelo más } \\
\text { frecuente. }\end{array}$ \\
\hline & Política. & $\begin{array}{l}\text { Monarquía, } \\
\text { república } \\
\text { democrática, } \\
\text { dictadura, } \\
\text { capitalismo, } \\
\text { socialismo... }\end{array}$ & $\begin{array}{l}\text { De acuerdo al } \\
\text { discurso y en } \\
\text { la realidad. }\end{array}$ \\
\hline & Lengua. & $\begin{array}{l}\text { Castellano, } \\
\text { náhuatl, } \\
\text { otomí.... }\end{array}$ & $\begin{array}{l}\text { Flexible o } \\
\text { inflexible }\end{array}$ \\
\hline & Religión. & $\begin{array}{l}\text { Católica, } \\
\text { cristiana, } \\
\text { musulmana, } \\
\text { etcétera. }\end{array}$ & $\begin{array}{l}\text { Confesión más } \\
\text { extendida. }\end{array}$ \\
\hline & $\begin{array}{l}\text { Medios } \\
\text { masivos. }\end{array}$ & $\begin{array}{l}\text { Canales locales, } \\
\text { canales } \\
\text { internacionales, } \\
\text { espectaculares.... }\end{array}$ & $\begin{array}{l}\text { Identificar los } \\
\text { mensajes que } \\
\text { favorecen o } \\
\text { rechazan algún } \\
\text { valor. }\end{array}$ \\
\hline
\end{tabular}

Si la historia es un campo de lo social, un pedagogo puede auxiliarse de otras herramientas para profundizar en las causas de la situación que amerite una intervención educativa. A continuación se expone otra tabla que facilita el diagnóstico inicial de un pedagogo. 


\section{ESTRUCTURASPERMANENTESDELASOCIEDAD/ANCLASDELAREALDADSOCIAL}

\begin{tabular}{|c|c|c|c|c|}
\hline $\begin{array}{l}\text { Identifica un } \\
\text { hecho. Ejemplo, } \\
\text { la esclavitud. }\end{array}$ & $\begin{array}{l}\text { Que originan } \\
\text { conflictos por } \\
\text { motivos de poder } \\
\text { o económicos, o } \\
\text { de prestigio, } 0 \\
\text { ideológicos o } \\
\text { religiosos, o de } \\
\text { relaciones } \\
\text { personales o por } \\
\text { falta de } \\
\text { conocimiento. }\end{array}$ & $\begin{array}{l}\text { Estos conflictos } \\
\text { surgen debido } \\
\text { a que se } \\
\text { piensa que la } \\
\text { persona es: }\end{array}$ & $\begin{array}{l}\text { El fin de } \\
\text { la vida es: }\end{array}$ & $\begin{array}{l}\text { Las motivaciones } \\
\text { o valores más } \\
\text { importantes que } \\
\text { orientan estos } \\
\text { comportamientos } \\
\text { son: }\end{array}$ \\
\hline $\begin{array}{l}\text { En el campo } \\
\text { económico. }\end{array}$ & $\begin{array}{l}\text { Quien tiene } \\
\text { más esclavos, } \\
\text { tiene más mano } \\
\text { de obra. }\end{array}$ & $\begin{array}{l}\text { Agente de } \\
\text { producción. }\end{array}$ & $\begin{array}{l}\text { Acumular } \\
\text { bienes. }\end{array}$ & $\begin{array}{l}\text { Lo que importa } \\
\text { es la riqueza. }\end{array}$ \\
\hline $\begin{array}{l}\text { En el campo } \\
\text { político. }\end{array}$ & $\begin{array}{l}\text { El que tiene } \\
\text { esclavos más } \\
\text { preparados, puede } \\
\text { controlar puestos } \\
\text { claves como la } \\
\text { distribución de } \\
\text { agua. }\end{array}$ & $\begin{array}{l}\text { No tienen } \\
\text { voz ni voto. }\end{array}$ & $\begin{array}{l}\text { Que se tome } \\
\text { en cuenta su } \\
\text { opinión en las } \\
\text { decisiones. }\end{array}$ & $\begin{array}{l}\text { Hay que imponer } \\
\text { los modelos. }\end{array}$ \\
\hline En la sociedad. & $\begin{array}{l}\text { Más esclavos, } \\
\text { más prestigio. }\end{array}$ & No cuentan. & Ser influyente. & Ser importante. \\
\hline En la persona. & Más poderoso. & Más servicio. & $\begin{array}{l}\text { Tener quien } \\
\text { le sirva. }\end{array}$ & Ser reconocido. \\
\hline
\end{tabular}

El esquema anterior permite analizar acontecimientos pasados, historia, y hechos presentes, hoy, para llevar a cabo el diagnóstico necesario. 


\section{LIBERTAD, ESPERANZA, IDENTIDAD, AUTOCONCEPTO}

Además del conocimiento de la sociedad, para un pedagogo la historia es testimonio de la libertad humana, tanto a nivel personal como grupal ${ }^{\mathbf{3}}$. La diferencia de culturas evidencia el uso de la libertad y la aplicación de la inteligencia de maneras diferentes. La diversidad cultural está enlazada con el uso de la libertad en el pensar y en el hacer, que no en el ser, que es dado e inmutable.

Por ello, para un pedagogo en formación, resulta interesante analizar lo que no es permanente de la naturaleza humana, aquello en lo que la humanidad ha plasmado el uso de su libertad para conocer e interpretar la realidad. El uso de la libertad está también asociado a la iniciativa, reflejo personal de la misma y estrechamente relacionado con la motivación interna. Para el pedagogo, la libertad es el antídoto frente al determinismo. Este tema, ejemplificado a través de hechos históricos, puede ser básico en la planeación de la intervención educativa.

Otro aspecto provechoso para el pedagogo es considerar la historia como fuente de esperanza en la humanidad. El análisis de sucesos ocurridos con abismos de maldad se atenúa con el de hechos contrastantes que mantienen la esperanza en que algunas personas individual o colectivamente - se agrupen para procurar el bien de sus semejantes ${ }^{4}$.

${ }^{3}$ Cfr. CROCE, B., La historia como hazaña de la libertad.

4 Ése es el caso de la $\bullet$ Cruz Roja Internacional•, •Médicos sin Fronteras, etcétera. 
Por definición, el pedagogo busca el bien de los demás y el conocimiento de la historia podría reforzar, en él, el ideal de transformar la realidad en beneficio de todos. La historia posee, en su acervo, múltiples ejemplos de que este ideal es posible y que la conciencia colectiva puede modificarse para excluir conceptos aberrantes como la esclavitud, considerada como algo natural durante milenios de historia, apoyados en la autoridad intelectual de Aristóteles.

Por último, si se considera que la historia es uno de los medios privilegiados para trasmitir la identidad nacional, la historia patria cobra en sí misma mayor importancia. La identidad es una construcción cultural consciente que tiene como fin unificar a los individuos de un grupo y definir el modo de reconocerse como miembros de una nación. Parte de la identidad nacional se basa en el pasado común que une a los integrantes de un grupo que decidieron aglutinarse en tomo a un proyecto político. En el caso de los mexicanos, la identidad nacional se basó en la identidad histórica que excluyó a la negritud como parte de la conciencia colectiva decimonónica ${ }^{5}$. La identidad cultural está constituida por las costumbres, la lexagua y la religión que unen, en el presente, a los miembros de ese grupo y que, a lo largo del tiempo y de la historia, conforman un modo de ser, de percibir la realidad, de comportarse, de relacionarse entre sí y con los otros. La historia es un buen medio para explicar la alteridad, fundamento de todo proceso educativo y base de la identidad grupal o nacional.

Cfr. CAStillo PAlma, N. A., Cholula. Sociedad mestiza en ciudad india. 
Por otro lado, la identidad colectiva es el cimiento del autoconcepto y la autoaceptación, indispensables para el cambio deseado y posible a través de la educación. Si el auto-concepto está equivocado, la intervención educativa es indispensable. Tal es nuestro caso, el de los mexicanos. Reinterpretar $y$ reconstruir la identidad a través de la historia, es abrir las posibilidades de la transformación deseada para construir un mundo con menos diferencias entre los humanos, sin importar la etnia de origen o la mezcla resultante.

En otro aspecto, la historia comprueba que cada habitante de la tierra desciende de una cadena de sobrevivientes de desastres naturales y dificultades acarreadas por las creaciones humanas (como las guerras biológicas).

Es sabido que la demografía constata que la clase privilegiada históricamente se reproduce menos que la clase baja. De ahí se deduce que los habitantes del planeta, en el primer cuarto del siglo XXI, somos descendientes de individuos superdotados de la clase fuerte biológica que sobrevivió a terremotos, guerras, revoluciones, etcétera, que provocaron miedos y angustias o depresiones colectivas que dieron como fruto hambrunas, mortandad, descenso de la natalidad... Baste recordar la disminución de la población en América al contacto con los europeos del siglo XVI.

\section{TRES EJES}

El profesor de historia de la educación, podrá mejorar su tarea docente si tiene claros los siguientes ejes para su actividad: 
1. El para qué de la educación: Se refiere fundamentalmente al fin de la educación o a la meta que se persigue en determinado modelo social. Después de muchos años de lecturas ${ }^{6}$, puede retomarse lo que algunos autores llaman la triple función educativa: a). Socialización o adaptación de la persona a la sociedad a la que pertenece. En este rubro se hallan el idioma, la vestimenta, la comida, las costumbres, los rituales y todo aquello referido a la vida cotidiana. b). La capacitación para el trabajo, que normalmente se inicia de un modo informal en el hogar y que, más tarde, adquiere características especializadas. c). La moralización o educación para el bien que por lo general inicia en el ámbito del hogar de una manera informal y que, en algunos casos, se traslada al templo, como en Sumeria y Egipto e Israel.

2. El qué La fecha más importante de la historia es la del cumpleaños de cada uno, porque ahí se inicia la historia de la educación personal. Por eso, todo es importante en la historia de la educación. Seleccionar los contenidos es una tarea ingrata que deja en el acervo de lo no expuesto una gran riqueza de la humanidad. ¿Por qué proponer a los alumnos apropiarse de una parte y no del todo? ¿Por qué limitar la oportunidad de conocer a los pensadores más influyentes en la educación de la humanidad? El límite que se tiene es el tiempo, recurso vital no renovable, y por tanto apreciado al máximo. La selección es indispensable. Se sacrifica el gusto propio y se integra el temario según las coordenadas de tiempo y espacio de la cultura occidental en la que está inmersa 
la cultura mexicana. Se añade, con el tiempo, una novedad didáctica para analizar la realidad: seleccionar en cada tópico: a) actores; b) escenarios, y c) temática. Para la historia general de la humanidad se incluye el pensamiento clásico. Se agregan autores importantes de los últimos cincuenta años '.

3. El qué en la historia de la educación en México: La historia es continua, como la vida, por ello hay que iniciar con el México antiguo, y a vuelo de pájaro, arribar en cada sesión al día en que vivimos. Hace veinte años, el término ruina para designar un vestigio arqueológico era adecuado. Hoy resulta despectivo. El esplendor de Teotihuacan, Tajín, Monte Albán, Tula, etcétera, no es ruinoso. Es inspirador de los ancestros biológicos de los mexicanos contemporáneos. Las preguntas para cimentar el pensamiento crítico respecto a la raíz india de la cultura mexicana pueden sintetizarse en los siguientes ejemplos: ¿Qué se requirió para planear y construir esas ciudades? Trabajo personal y en grupo. ¿Quién lo hizo? Lo indios que vivían en ese tiempo. ¿Cómo lo hicieron? Con esfuerzo constante y organización, con disciplina. Puede elaborarse una lista de esfuerzos sumados para lograr el esplendor de las ciudades prehispánicas y puede proyectarse al día de hoy esta cultura del esfuerzo en el trabajo comunitario.

7 Un pedagogo contemporáneo en México debe conocer los postulados de la educación liberadora de Paolo Freire y la influencia en el material que el INEA elaboró por décadas. ¿Puede ignorar que el conductismo de Skinner es la base para elaborar los tutoriales de los programas de cómputo? Tal vez, por ello, contar con un CD-ROM que incluye la lista de los autores reconocidos universalmente es un apoyo importante. Se enriquece con datos biográficos del autor y con un fragmento de alguna de sus obras, particularmente explícita respecto a la educación. El proceso para recopilar materiales fue largo y enriquecedor. Propició el diálogo con profesores reconocidas como María Pliego, Héctor Lerma y Jorge Medina. También favoreció la interacción con jóvenes que mejoraron y pulieron la idea original: Claudia Ortega, Héctor Miranda, Roberto Carlos Martínez y Crisol Ortega. 
En el apartado de la historia colonial, vale la pena incluir el proceso de castellanización, iniciado en el siglo XVI e inconcluso en el siglo XXI. El cambio de lengua y de religión transformó la cultura colectiva. Tanto una como la otra se convirtieron en medios de cohesión social. También durante la colonia se construyeron templos católicos de grandes dimensiones y profunda belleza. Se edificaron con el trabajo comunitario de los habitantes de ese entonces. Puede comprobarse que el trabajo estuvo presente y lo está ahora.

En el apartado de la historia contemporánea, sería recomendable enfatizar los modelos económicos vigentes en el país de 1920 a 1992. Sus logros, como el Seguro Social, la cobertura escolar, la electrificación de la mayor parte del país, están a la vista. Con el modelo que surge a partir de la firma del Tratado de Libre Comercio, surgió una revolución cultural que todavía no ha terminado. El pedagogo contemporáneo tiene el gran reto de capacitar a millones de mexicanos que ya no están en el medio de la educación formal, sino en el medio informal, para ser productivos de acuerdo a la economía internacional de la que no pueden sustraerse.

4. El cómo: Este rubro abarca todo lo relacionado con el material didáctico. Hace veinte años era clásico el uso del pizarrón, el gis y el borrador. Este medio tiene una flexibilidad enorme y permite que el profesor adecue a sus discentes el discurso que quiere que ellos capten e integren en su saber y su vivir. La desventaja: la caducidad del mensaje que se desea transmitir. El borrador termina con la magia de la transmisión de conocimientos. 
El pizarrón presentó una mejora: fondo blanco y plumones de agua de varios colores que permitían la combinación de tonos y hacían que los alumnos que aprendían por el canal visual preferentemente, tuvieran mejores símbolos de la conceptualización transmitida. El -rotafolio» fue, en su momento, un excelente medio para presentar las ideas ya ordenadas y con la secuencia deseada. Su desventaja: la falta de flexibilidad. Se preparaba para un grupo ideal que quizá no era el que estaba frente al docente. Además, se daña fácilmente; no puede almacenarse por su tamaño; el material es deleznable. Hay demasiado tiempo y esfuerzo del docente, recursos escasamente reciclables.

La crestomatía o selección de textos de especialistas que auxiliaran al alumno a apropiarse del conocimiento y a discutir en clase la postura de los especialistas, se trabajó para la materia de Historia de la educación en México y fue tarea de la entonces joven profesora Claudia Fabiola Ortega Barba, en 1999.

El «proyector de cuerpos opacos• fue un inicio de lo que sería después el mundo digital. Este instrumento permitía compartir con un grupo la imagen o el texto que podía ilustrar una idea. Fue el inicio de la cultura de la imagen, característica de la cultura del inicio del siglo XXI. Pesados y poco prácticos, se extinguieron pronto. Los sustituyeron los «retropoyectores de acetatos», el apoyo más utilizado antes de que contáramos con el «cañón. y la «lap».

La televisión con la videocasetera, prestó un servicio invaluable para dar a conocer a los alumnos la memoria gráfica de la Revolución y otros documentales que enriquecieron su 
conocimiento del pasado histórico que comparten como mexicanos.

La revolución en el campo del material didáctico se popularizó con las presentaciones elaboradas en programas de la paquetería internacional (power point). Se transformaron los medios, pero no el fondo.

Recientemente, en el año 2006, el profesor de historia cuenta con un recurso multimedia reconocido a nivel internacional: la «Enciclomedia». Desarrollada en México por mexicanos, logró la alianza con Microsoft, patrocinadora de «Encarta». La combinación del concepto enciclopedia con multimedia, enriqueció y revolucionó el material educativo nacional. La riqueza de los materiales es indescriptible. Todos los recursos didácticos: textos, videos, diccionarios, audios, mapas, etcétera, etcétera, se hallan al alcance de los alumnos de educación primaria en la República Mexicana.

Este material, desarrollado por el ILCE (Instituto Latinoamericano de la Comunicación Educativa), se graba o guarda en un disco duro de gran capacidad en el servidor de la escuela, a fin de que los docentes puedan consultarlo desde el salón de clases. De este modo, no se necesita una conexión a Internet (que supondría una cuota mensual por este servicio) y se complementa el equipo con un pizarrón electrónico instalado en el aula.

Éste no es el caso de la Universidad Panamericana que tiene acceso a Enciclomedia a través del Centro de Cómputo y, además, en una computadora portátil para facilitar la consulta en las diversas aulas. La universidad, a través del 
departamento de innovación educativa, de la Facultad de Pedagogía, firmó un convenio con el ILCE para estudiar el material y su uso por estudiantes de educación superior. La computadora aumenta su funcionalidad al conectarse a un cañón, para socializar la imagen y el contenido.

Después de una revisión de los materiales para la enseñanza de la historia en Enciclomedia - que incluye mapas históricos, línea del tiempo, «mapoteca» y acceso a una enciclopedia-, queda a la vista que la utilización de este recurso enriquecerá al docente y al alumno en la historia general de la educación y en la historia de la educación en México. Los materiales, diseñados para alumnos de $5^{2}$ y $6 \mathrm{Q}$ año de primaria, pueden utilizarse perfectamente por los alumnos de educación superior. Lo que cambia es el nivel de discusión de los materiales. El nivel de análisis que lleva a interpretar los datos y a utilizarlos para realizar el diagnóstico. 


\section{REFERENCIAS BIBLIOGRÁFICAS}

LEWONTIN, Richard cut al., No está en los genes. Racismo, genética e ideología., México., CONACI LTA. G rija 11)0, 1991.

HOFFNER, Joseph., Manual de doctrina social cristiana. Madrid., Rialp., 1974; LLANO, Alejandro., La nueva sensibilidad., Madrid., Espasa-Calpe., 1989.

CROCE, Benedeto., La historia como hazaña de la libertad., México., FCE., 1979.

CASTILlO PALMA, Norma A., Cholula. Sociedad mestiza en ciudad india., México., UAM., PyV.. 2001.

MANACARODA, Mario Alighiero., Historia de la educación., México., Siglo XXI., 1987. 